\title{
Strategy and Structure in the Italian Fashion Industry: A Case of Internationalisation
}

\author{
Ernesto Tavoletti
}

Received: 9 November 2008/Accepted: 3 April 2009/Published online: 22 August 2009

(C) Springer-Verlag 2009

\begin{abstract}
Many SMEs in the Italian fashion industry do not find a fit between strategy and structure able to open them to growth and new opportunities in emerging international markets. Through an in depth analysis of a successful business case, a contribution is made to the study of strategy-structure fit in the Italian fashion industry, with particular reference to the international growth phase. The case confirms the causal link between strategy and structure. However, the development route in the fashion sector does not follow the historical model analysed by Chandler: Uppsala's model of incremental and cognitive internationalisation appears to be the more appropriate reference for Italian "industrial networks", characterised by creative dynamics that are constantly evolving, and strong needs for structural flexibility and strategic change.
\end{abstract}

Keywords Strategy $\cdot$ Structure $\cdot$ Internationalisation $\cdot$ Fashion industry

JEL Classification $\mathrm{M} 16 \cdot \mathrm{L} 20 \cdot \mathrm{L} 21$

\section{Introduction and Theoretical Debate}

The theme of the relationship between strategy and organisational structure is first laid out in the work of Chandler (1962), through his analysis of the evolution of five principal US industries in the first half of the twentieth century.

In the international debate preceding 1962 it was not customary to consider the whole of Chandler's decisions as "strategy": the work of Smith and Christensen (1962), only 1 year earlier, even though speaking of "business policy", inductively

E. Tavoletti (四)

Department of Studies on Economic Development, University of Macerata, Macerata, Italy

e-mail: ernesto.tavoletti@unimc.it 
analyses business "strategies" and their implementation but it does not provide a conceptual framework.

Chandler explicitly introduces the concept and definition of "strategy" as a business' choice of basic aims and long term objectives, the choice of criteria of action and the type of allocation of resources necessary to realise the aforementioned objectives. " "Structure" is defined as the organisational design with which the business is managed, specifying that such a design, whether formal or informal, has two aspects: the lines of authority and communication between the different administrative functions and those in charge; the information and data that flow through these.

Chandler's text therefore describes the relationship between strategies, structure and processes, identifying a direct connection of causality: the strategy determines the structure through changes in the organisational design.

Chandler identifies the succession of four strategies: (1) expansion of volume and needs of administrative functions; (2) geographical expansion and distribution of the same function in more units that are further apart; (3) vertically integrated business even with decentralised functions; (4) divisionalised company.

Scott (1971) introduces a model that considers the changes within the competitive context of the twentieth century and which differs from Chandler's especially with regard to divisional structure and diversification strategy. Scott differentiates between "divisionalisation", as a choice of an efficient structural typology, and "decentralization" as a policy measure of operating within the structure. Scott notes the presence of divisional structures that are crossed by diverse degrees of decentralisation, within the range of diversification strategies that are by nature always more financial and focused on the profitability of the group system.

Channon (1973) highlights, in the British case, the low significance of the growth phase through vertical integration and proposes a model with three specific "strategic categories", highlighting stickiness and resistance in the passage from one to the other: businesses with a sole product, businesses with a dominating product, businesses with various diversified productions.

Following Chandler's (1962) study on US industry and that of Channon (1973) on British industry, others have adapted the model to the individual national specifics (Suzuki 1985 for Japan, Pavan 1976 for Italy) definitively releasing the study of the "structure" from the rigid Weberian determinism and finally grounding it in the external institutional environment.

The Swedish school, particularly with Uppsala's model of internationalisation (Johanson and Vahlne 1977), brought attention to the importance of the cognitive processes on the incremental decision-making mechanisms and on the associated gradualness of the emerging courses of internationalisation. According to the Uppsala model, given certain cognitive conditions, businesses typically begin to expand internationally with direct export to a single country, through an agent; they

\footnotetext{
1 It will later be Ansoff who finally consolidates the use of the term "strategy" in management studies (Ansoff 1965).
} 
later establish a sales subsidiary and finally, in some cases, a production establishment.

The ensuing debate has challenged Chandler's theoretical framework and the causal strategy-structure relation, suggesting that strategy can emerge, occasionally, from a given structure (Hall and Saias 1980) or as the result of a contextual development and emerging from interconnected structures and strategies. Despite that, the value of Chandler's pioneering work in terms of initiating and systematising a new trend of research, that moved away from Weberism, still remains unquestioned.

Researchers of the internationalisation of businesses have closely examined the subject of the relation between organisational structure and strategy (Stopford and Wells 1972; Franko 1976; Egelhoff 1988) pushing progressively forward towards a concept of the firm understood as an "organisation set" (Aldrich and Whetten 1981). Such a trend of research, that led to the definition of a "network" form (Tichy et al. 1979; Snow et al. 1992) has shown to be particularly suitable for research into the internationalisation of Italian businesses (Boari et al. 1989; Lorenzoni 1990) that are characterised by small sizes and by territorial systems that are well integrated (district, cluster, pole). Local and district systems in fact, prove to be the basic axis of Italian exports, even showing the capacity to experiment with new forms of organisation, like the multi-located district (Zucchella 2006).

On the scientific level, the main contribution of Italian economists to the research of internationalisation is the analysis of the businesses' starting "place", whether these be districts or non-district local systems (Becattini 2000; Bellandi and Caloffi 2006; Dei Ottati 2003; Rullani 1997), rather than end "places".

Instead, the Italian business school has focused its research on the small internationalised company, identifying in it not only a transitory development typology, but a form of real presence in foreign markets (Pepe 1984; Cafferata and Genco 1997; Cafferata and Mensi 1995; Golinelli 1992).

Recent Italian studies, using Uppsala's model of internationalisation as a basis and taking into account the described specifics of the Italian reticular production model, have created a model of internationalisation in stages, based on the model of sub-supply; by analysing the processes of relocating the fashion sector towards Eastern Europe they encountered three different phases: (1) traditional sub-supply; (2) co-ordinated sub-supply; (3) relocation of the supply system (Camuffo et al. 2006).

These studies highlight that the Chandlerian causal connection between strategy and structure remains unchallenged: the flexible and reticular structure of our small and medium-size industries adapts itself constantly and rapidly to the strategies of internationalisation of businesses. However, the evolutionary path of the strategystructure relationship in the fashion sector does not follow the historical model of the great North American industries as described by Chandler for the motor and chemical sectors: Uppsala's model of incremental and cognitive internationalisation appears to be the most suitable reference for the Italian "industrial networks" of the fashion sector (Johanson and Vahlne 1990). 


\section{Hypotheses Setting and Research Design}

This work adds a contribution to the study of the strategy-structure relationship of businesses orientated towards exporting in the made in Italy fashion sector, with particular regard to the decision phases of the business' international growth.

The choice of the fashion sector was motivated by its current relevance to the Italian balance of payments and because it represents a sector in which our small and medium-size industries could maintain a competitive advantage in the future.

Choosing the strategy-structure subject derives from its relevance in the debate and its infrequent application to the "industrial networks" of Italian businesses in the fashion sector.

Our research proposal is if the Chandlerian strategy-structure paradigm is applicable, at least partly, to the growing Italian businesses in the fashion sector that are opening to internationalisation.

Our first hypothesis is that the causal strategy-structure connection remains valid and suitable for the study of the processes of internationalisation of Italian businesses in the fashion sector: the reticular structures of our businesses adapt themselves to the emerging strategies of internationalisation.

Our second hypothesis is that the classical development phases of the Chandlerian paradigm do not adapt themselves to the "industrial networks" of Italian businesses in the fashion sector: Uppsala's model of incremental internationalisation appears to us to be the most suitable interpretative paradigm (Johanson and Vahlne 1990) for the internationalisation of these businesses.

With regard to the methodology of research, we follow the same methodology adopted by Chandler: the study of the evolution of the strategy-structure relationship requires the observation of the business in its growth, not separated from its environment and its complexity. It is in this sense that we intend to contribute to the debate with a case study carried out during the course of 2007.

The research strategy is that of Yin (1989) and the unit of analysis is Sixty Group, a successful business in the made in Italy fashion sector, located in Central Italy.

The choice of Sixty Group, a profile of which is outlined in paragraph three, is determined by its accessibility and its significance to the subject of internationalisation: a case of a successful Italian business in the fashion sector, that managed to grow and go through a process of structural change for internationalisation.

The study has no objectives of inferential generalisation with regard to the population of Italian businesses in the fashion sector. Instead it seeks to provide an analytical generalisation of the strategy-structure relationship within the case study, with the aim of examining whether the two formulated hypotheses (and their associated theoretical paradigms: Chandler's strategy-structure model and Uppsala's model of internationalisation) are to be proved correct or invalid.

If the evolution of the strategy-structure relationship in the process of internationalisation of Sixty Group verifies the above mentioned hypotheses and paradigms, this work will have contributed to confirming the interpretative validity of said paradigms and to understanding the international development of a successful Italian business in the fashion sector that knew how to grow beyond its small size at an international level. 
It is hoped that further studies apply the same hypotheses to other business cases within the fashion sector.

\section{The Case: Strategy and Structure}

Sixty Group (from now on "Sixty"), whose first company was established in 1989, is currently a very important player within the worldwide sector of planning, production and marketing of clothing articles in the segment commonly referred to as "casual wear".

Sixty is the producer and distributor of brands including Miss Sixty, Murphy\&Nye, RefrigiWear, Energie, Killah, Sixty, Richlu, Dake, Waxy, Baracuta, Kblost, Bandits du Monde and more recently, Roberta da Camerino.

The group distributes in all the countries of the world with the exception of a few minor Asian countries and the African continent (where it is only present in Egypt, Morocco and South Africa). Its retail outlets in the world, including owned shops, franchising and multi-brand independents, are estimated at 7,000 units distributed over 90 countries. The owned retail outlets and mono-brand franchises in the main cities of the world are around $380 .^{2}$

The total turnover of the group on 31 December 2006, including also minor companies, is around 700 million euros. The total of employees and collaborators is around 1,500 individuals.

Sixty represents a success story in the Italian small and medium-size industries of made in Italy. Started in 1989 with only the energies and talents of the entrepreneur, without any significant initial investment, the company has progressively grown as far as achieving, within the span of 15 years, an important place, firstly in the national market and later the European and non-European markets.

From the very beginning, the company's strategy was not calculated but "spontaneous" (Mintzberg and Waters 1985). The entrepreneurial idea begins, in fact, casually in Rome, with the meeting of a creative talent (Vittorio Hassan) and a managerial talent (Renato Rossi). As Vittorio Hassan recalls in an interview for Mig Pig on 2 February 2004 "I was doing something completely different. I was attending the academy, I was painting. I had an exhibition. I didn't sell anything. I tried doing something else, I used to go to Porta Portese on a Sunday to sell things, then to another market. After going through all of this, I opened a shop. My partner saw that things were going well and he made me open another". Initially the business dealt with the import of articles popular in the USA that were not yet widespread in Italy: "In 1982, '83. I started buying popular things because everyone was wearing the same clothes, the same brands. It was the time of the first All Stars, I was the only one in Lazio that sold them, I had the exclusive. The first Timberlands, the first Levis' 501, that no-one had yet. All imported stuff. The first

\footnotetext{
2 Among the retail outlets in the main cities outside of Europe, the following can be pointed out: Tokyo (2), Shanghai (5), Hong Kong (5), Seoul (2), Taipei (9), Bangkok (2), Singapore (1), San Paolo (3), Rio De Janeiro (2), Buenos Aires (2), New York (1), Los Angeles (3), San Francisco (1), Ala Mohana Hawaii (1), Moscow (4), New Delhi (1), Mumbai (1), Dubai (5), Riyadh (1), Cairo (1), Rabat (1), Johannesburg (1), Cape Town (1), Damascus (1), Tel Aviv (1), Melbourne (1).
} 
Fruit of the Loom T-shirts, sweatshirts with hoods. Many were American imports, clothes that you could not see around, when dinosaurs still roamed, years and years ago". Then the desire to find innovative solutions and the creative ability pushed the business from commerce to handicraft: "I could no longer find the things that I needed, so with a seamstress from the shop, the one that did repairs, I tried some things. I had some old used jeans, very small sized Levis'. I had made some material inserts, ethnic, a bit Mexican. The trousers widened, they increased in size and they were very unusual. They worked. It was 1984, 1985". The success of the handicraft products and the strong demand of young people rapidly produced the industrial activity with the creation in 1989 of Sixty S.r.l., then Sixty S.p.A. but the spirit and strategy of the company remain unchanged: "We work mainly by intuition, spontaneously, on the strength of the energy that is unleashed. It's a lot about the enthusiasm, the excitement that grows, explodes and excites you. I am careful with every piece that I create. We try, even today, to do everything unconsciously without being weighed down by anxiety over sales. We try to keep ourselves 'light and irresponsible"'.

"Lightness" is a constant factor in Sixty's strategy: satisfying the clothing needs of teenagers through the constant application of innovation and creativity, remaining "light" within the production structure and always ready for change.

Product planning and commercialisation, from the two respective entrepreneurial souls of the founding partners, remain the main activities in Sixty's value chain. Product industrialisation has, in fact, maintained the handicraft spirit through constant research of ideas and products capable of satisfying the ever-changing clothing needs.

The business strategy focused on the innovation needs of the final consumer has required a socio-technical structure that is as flexible and light as possible, that draws from outside the human and production resources that are constantly more appropriate, whether these be creative talents, brands to release or productive efficiencies of sub-suppliers. Client demand and the positive managerial performance pushed Sixty to buy new brands and new production capacities. The three main companies that joined Sixty S.p.A. in the course of time were started to purchase the individual brands to be re-launched (Sixty Active S.p.A.: turnover of 100 million euros, Murphy\&Nye brand; Cruz S.r.l.: turnover of 40 million, RefrigiWear brand) or to buy manufacturing capacity (Sixty Factory S.p.A: turnover of 70 million) to keep separate from the core business of product planning and commercialisation.

The management of recently acquired brands through separate individual companies allowed for a reduction in risk to the company, a more focussed monitoring of the brand's economic character and strategies, helping to keep Sixty S.p.A.'s main structure "light".

Sixty S.p.A (turnover on 31 December 2006 of 470 million euros) has a typical functional structure. The other companies of the group only have main functions and depend on Sixty S.p.A., through service contracts, for the remaining functions (control of management, finance, strategic marketing, management of personnel, operations). 
Industrial activity and co-ordination of the chain of sub-supply are concentrated in Chieti while creative activity is entrusted to the style office in Rome.

The main objective of the style office is to anticipate in a systematic way the seasons of fashion to keep ahead of changes in taste of the new generations that demand continual innovation. The objective is reached through a continuous turnover of young talent from all over the world, with curiosity and with different points of view, to experiment. This has allowed the group to create collections of great originality that are a reference point for young consumers.

Sixty has recently entered into the shoe wear sector with the brands of Miss Sixty, Energie and Killah and it co-ordinates the technical and stylistic image respective to leather goods, glasses and perfumes.

In June 2007 the group purchased the historical Venetian brand "Roberta di Camerino" and set up "Roberta di Camerino S.p.A" in Venice, thus entering into the luxury goods sector for the first time.

\section{The Strategy of Internationalisation and the New Structure}

Sixty's strategy of internationalisation was spontaneous and not planned. At the end of the 1980s and at the beginning of the 1990s there was a commercial expansion, especially in the national territory, because of the greater knowledge of the domestic market, the geographical proximity and cultural affinities between producer and consumer. Later, the success on the national level led to increased exports to culturally similar countries and progressively further away, first in Europe and North America, and then in the East and the rest of the world. ${ }^{3}$ The sales make-up between the Italian market and exports on 30 September 2007 was the following: 29\% Italy, 42\% Europe, 13\% United States, 11\% Far East, 5\% other countries. Recent trends showed a growing weight of the foreign component compared to the national one.

The production installations and production agreements followed the commercial penetration and occurred first in the national territory, then in Eastern Europe and the Mediterranean basin, and finally in the Far East and China.

A distinctive feature of the Chinese "casual wear" market is price competition. This is caused by both the extensive low cost local manufacturing base and the exponentially growing supply of foreign brands that normally use the price variable in the launch phase. Foreign luxury brands are able to maintain a price differential with regard to local brands but in the case of "casual wear" prices tend to level out to those of local brands and made in China international brands.

For the above reasons, Sixty's strategy in China opted both for the acquisition of the historical Venetian brand of the luxury goods sector "Roberta di Camerino", with the establishment of "Roberta di Camerino S.p.A.", and for the outsourcing to

\footnotetext{
${ }^{3}$ With regard to marketing abroad, Sixty uses both direct and indirect channels and for some of the main foreign markets holds control of the foreign marketing companies. Sixty S.p.A. holds especially the following controlling interests: Sixty Scandinavia AS (100\%); Sixty Deutschland Gmbh (100\%); Sixty Brasil Ltda. (99.9\%); Sixty Argentina SA (95\%); Sixty Spain SL (99.5\%); Sixty Portugal Lda. (100\%); Sixty Belgium SA (99.8\%); Sixty Netherlands BV. (100\%); Sixty Canada Inc. (100\%); Sixty France sàrl (99.5\%); Sixty Polska Sp.zo.o. (99\%); Sixty Log srl (100\%).
} 
China of production of some brands of "casual wear". The biggest financial effort is currently positioning of the brand image, necessary to justify a price differential with regard to local products.

The structure that has been in charge of commercial penetration and production installations in China since 2003, is "Sixty Far East Ltd", based in Hong Kong. This company controls: (1) the retail network with retail outlets in the main cities; (2) the wholesale business with a network of commercial agents; (3) production outsourcing. Because of the restricting provisions in force and because of the information asymmetry with local competitors, a partnership with an operator that is locally rooted and already equipped with production and retailing capacities was necessary; a company subsidiary assigned in Hong Kong, endowed with legal status, was in charge of the establishment and relationship with the Chinese subsidiary. ${ }^{4}$ The Chinese subsidiary employs a very streamlined structure: a central management; a retail area; a wholesaling area; an area dedicated to "product sourcing"; and some functions to support three areas (accounting and administration, marketing, IT and graphic design).

The commercial presence in China of the Sixty group has developed strongly from 2003 to today and the company numbers dozens of retail outlets and a good basis in the wholesale sector. Development prospects are especially linked to profitability, in relation to which the expansion of product sourcing activities is central.

The rapid international growth of the company both by the internal route, with the expansion of Sixty S.p.A. and by the external route, with the establishment or acquisition of Sixty Active S.p.A., Sixty Factory S.p.A. and Cruz S.r.l., has highlighted a greater need for co-ordination between the functional structures of the different companies. In the course of the group's development, in fact, in the absence of a more structured integration, the activity of co-ordination has been carried out by Sixty S.p.A., drawing to itself some of the more relevant functions.

During the course of 2007, with the aim of making the organisational structure of the company more efficient, the need arose to merge Sixty S.p.A with some minor companies $^{5}$ and to reorganise the latter according to the lines that follow (Fig. 1).

\footnotetext{
4 At the start of Sixty's commercial penetration in China in 2003, the People's Republic of China's regulations provided strong restrictions in the retail sector. Specifically it was not permitted that foreign companies wholly own retail operations in the internal market. It was therefore necessary to establish a Chinese legal company in situ, owned by fiduciary subjects and in charge of wholesale and retail marketing activities. The preferred technical solution, used by the same Gruppo Sixty, is that of establishing a company in the city of Hong Kong with special tax regulations, owned by the Italian mother house (Sixty Far East Ltd., in the above case), which in turn establishes a company in the rest of China (generally in Shanghai), owned by local fiduciaries and dedicated to wholesale and retail marketing ("Sixty China" in this case).

5 The group performed a merger, effective from 31 December 2007, between Sixty S.p.A., Sixty Active S.p.A. and Cruz S.r.1., thereby reducing the group's fundamental structure to two main companies, Sixty S.p.A., with nearly complete management of the brands and the group's central body of staff and Sixty Factory S.p.A., with a narrower industrial function. There remains, however, an autonomous business entity, Roberta di Camerino S.p.A. given the specifics of the luxury goods sector.
} 


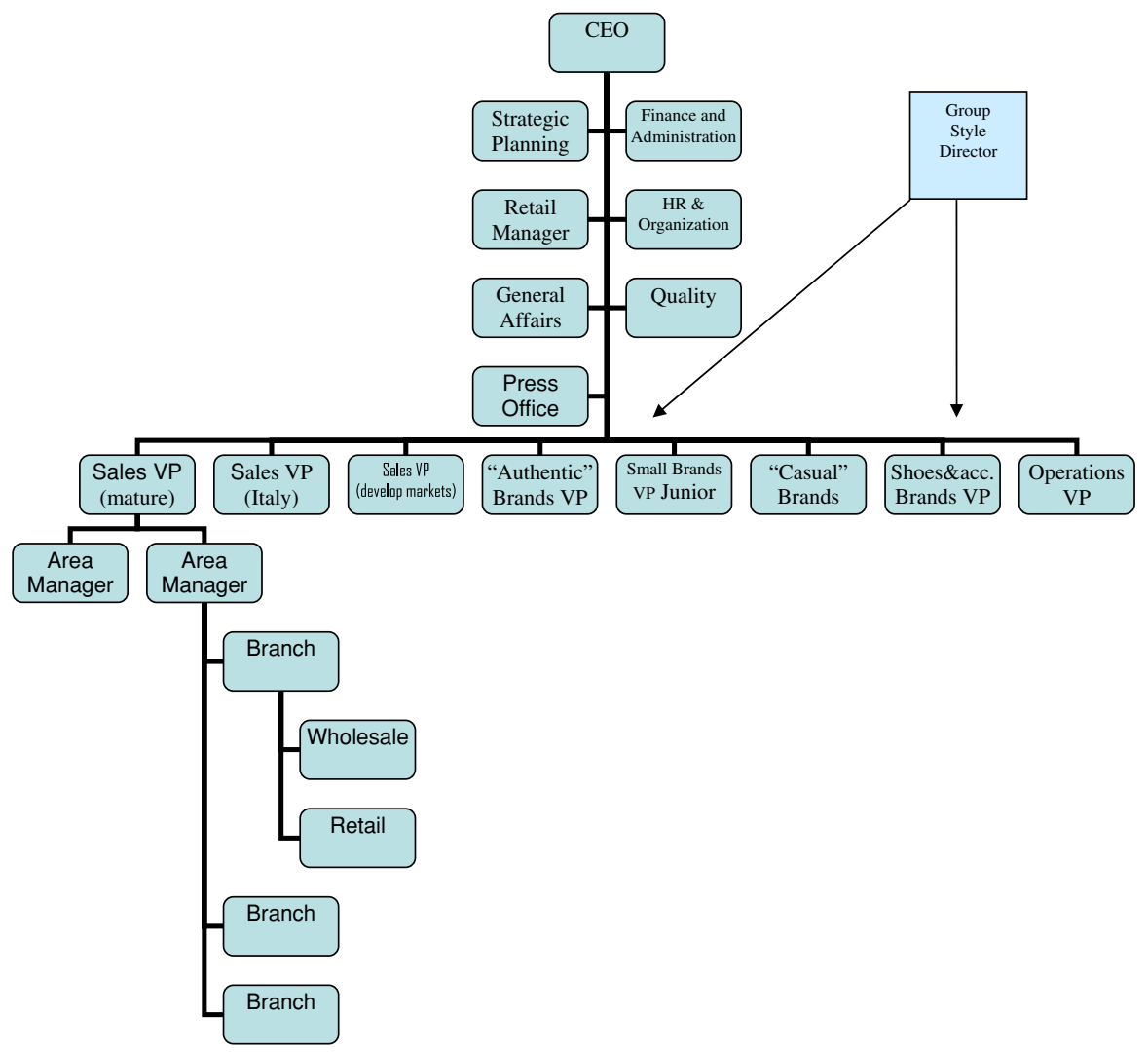

Fig. 1 The structure of Sixty S.p.A., following its reorganisation

The principal weakness in the existing structure is in fact, that many of the main company functions are duplicated and scattered in the different company structures of the group.

With regard to the sales function, the emerging need was that of a reorganisation through the appointment of a Sales Vice President for each one of the three main sales areas (Italy, Western Europe, developing countries and North America), with the aim of avoiding an excessive concentration of responsibility on a single manager and with the aim of making the impact more efficient on a more homogenous and limited area.

Each Sales Vice President is in charge of a sales division made up of branches involved both in retail and in wholesale and of one or more Area Sales Managers. These have the role of monitoring branch performance on behalf of the Sales VP and acting as a link between the branches and the Brand VPs.

The new organisational structure identifies in fact, four Brand VPs, three Sales $V P s$ and an Operations VP, all subordinate to the CEO and, in the case of the Brand $V P s$, also to the creative figure of the Group Style Director who manages Rome's Ufficio Stile. 
The Operations VP's responsibility is the industrial development of the product, purchasing, production and logistical functions.

Brand VPs are responsible for brand strategy, style, communications, research and development and brand marketing, under the co-ordination of the CEO and the Group Style Director. Hierarchically subordinate to the Brand VP, Brand Managers can be appointed for the individual brands.

With regard to the reorganisation of retail, a Retail Manager was appointed to be the central figure, to be a link between the CEO and all the VPs. Responsibility for the following activities is allocated to the Retail Manager and his departments: analysis of sales, order and stock related data; company design and image; merchandises; retail operations (store information data base, policy); planning, control and contracts related to the whole retail sector (franchising contracts, rent monitoring); editing the corporate Retail Plan.

The process of defining the corporate Retail Plan, coordinated by the Retail Manager, includes the following main steps: (1) Brand VPs propose the Brand Retail Plans for each brand, suggesting objectives in line with the strategic guidelines of the Retail Manager; (2) the Brand Retail Plans are discussed jointly among all the Brand VPs and Sales VPS under the co-ordination of the Retail Manager (in this phase, through the Sales VPs, the Branch VPs identify opportunities and new locations); (3) based on the existing negotiation between the VPs, the Retail Manager, carrying out a function that is both advisory and information gathering, proposes a corporate Retail Plan to the CEO, highlighting conflicts and unresolved problems; (4) the CEO resolves problems and approves the corporate Retail Plan with support from the Chief Financial Officer; (5) the Retail Manager oversees the implementation of the corporate Retail Plan.

To summarise and compare the main duties of the individual figures, we have the following picture:

- Retail Manager: proposes the retail strategies for the individual brands and geographical areas; draws up the corporate Retail Plan and is in charge of its implementation; is involved in developing the retail network; co-ordinates the retail sector on behalf of the CEO.

- Sales VP: discusses and collaborates in drawing up the Retail Plan supplying the Retail Manager and the Brand VPs with information with regard to branch performance and retail in the mentioned markets; drives and controls branch performance with support from the Area Manager.

- Brand VP: draws up the Retail Plan and sets brand objectives according to the strategic guidelines provided by the Retail Manager; discusses and collaborates in drawing up the corporate Retail Plan providing Retail Manager and the Sales $V P$ s information regarding brand performance; elaborates opportunities for the brands and recommendations for new shop locations that come from the branches.

- Branch Head: is responsible for profits and losses in the assigned area.

- Area Manager: is the linking element between several branches and Sales VPs.

With regard to the logistical function, the supply chain was put to the test by the rapid success of the group, and the need rose to adjust from a traditional functional 
approach to a management by processes able to better adapt itself to the periodic launch of sample collections.

In the new structure, the supply chain will be managed by the VP Operations, at the head of which will merge existing units (purchasing of raw materials, raw materials warehouse, production, general purchasing, shipping) and new units (supply chain Brand Account, operations costs management, planning) will merge.

Brand Account inside the supply chain will act as an interface with the rest of the company with regard to the production and logistic situation of the brand products. Its interlocutors are the Sales VPs, the Area Sales Managers and the branches.

The new operations planning unit will be entrusted with the strategic management of the suppliers (scoring, scouting, market share).

Finally, the operations cost management will take care of the budget relative to production, of determining the hourly cost and of monitoring and reporting production costs.

The branch structure will take into account the specifics of the individual entities, envisaging nevertheless, a standardised structure that will be adaptable to different situations. The large branches will generally have a Managing Director who will be responsible for a Retail Manager and a Wholesale Manager. Three or four branches, depending on size, will be co-ordinated by an Area Sales Manager on behalf of a Sales VP.

The Area Sales Manager will control a more restricted geographical area than the Sales VP, strengthening branch control and monitoring capacity. This is in fact an element that reduces the distance between branches and Sales VPs, also providing technical support to the latter.

The central body of staff at Sixty S.p.A. will include already existing units that need to be reorganised (finance and administration, human resources, quality office, Retail Management) and new units (strategic planning, general and legal affairs, press office).

A central finance and administration office is made necessary because of the growing number of reports and communications between the administrative offices of the different companies. The new structure will therefore introduce the figure of the Chief Financial Officer (CFO) who will lead the accounts department, the management control department and credit department with the associated responsibility of the credit policy. Gathering all of the accounts and financial information within a sole department and under a sole head should increase the coordination, generate economies of scale in the individual administrative activities, eliminate duplications, increase efficiency of functions as a whole, facilitate the control of basic macro-variables (circulating capital, commercial credit) and introduce with, the figure of the CFO, a sole financial interlocutor towards the outside.

The activities that are included in the function of "General Affairs" (facility management: reception, corporate building and structure management; non-core purchases: cars, consignments, fittings; legal department), are currently dispersed between the different companies of the group. The main objectives of merging into a sole department are to reclaim efficiency, the greater control and co-ordination of 
costs related to this area, the increase of a united buyer's contractual power, economies of specialisation and economies of scale.

Currently the planning strategy occurs on a non-formal basis. The establishment of a strategic planning unit should allow for better analysis of a competitive environment that is becoming more complex, support the CEO, globally manage the group brand portfolio, co-ordinate the position of brands, bring critical data to the attention of the CEO to, support the CEO in measuring performance of the group and its individual parts, identify new business opportunities, rendering the process of strategic formulation more rational, aware and informed.

With regard to relations between the two macro-areas of business, sales and production, in other words between Operation VP and Sales VP, the latter directly negotiate with the former, on a contractual basis, all that concerns logistics and production, so as to have a clear allocation of responsibilities.

\section{Analysis: Strategy and Structure in the Process of Internationalisation}

The development of Sixty's strategy-structure fit confirms our first hypothesis, or rather, the causal connection in which strategy determines the structure of the company (Chandler 1962). The strategy geared towards satisfying the everchanging clothing needs of young people, through continuous research of creative and productive solutions in outsourcing, determines a light organisational structure with a flexible sub-supply network, both in the initial phase of domestic development and in the following one of internationalisation. In the phase of national and European growth, the structure is organised around individual brands, with separate companies and with the co-ordination of a leader firm, to encourage maximum flexibility. In the following phase of international development outside Europe, the structure is reorganised, on a geographical and brand basis, to encourage the co-ordination of a more complex international strategy.

Structural development cannot in fact be entirely traced back to any classical British or North American paradigm (Chandler 1962; Scott 1971; Channon 1973). Sixty's evolution is in fact to be read with the theoretical references of the national tradition and in that peculiar configuration of business networks and leading businesses (Lorenzoni 1990), territorially rooted and geared towards export, that may constitute the only distinct and original elements of the Italian industrial tradition.

Sixty's structure, intended as inclusive of the suppliers' manufacturing base can effectively be read with the concept of the "network" company (Thorelli 1986), with a variety of subjects, stability of transactions and structured exchange, due to the coordinating role of the leading company (Lorenzoni 1990).

The first phase of the group's development from 1989 to 1993, with the creation and growth of functions within Sixty S.p.A., facing a rapid expansion in volume, could be traced back to the first stage of the Chandlerian model but already from 1993 the progress follows a different route of external growth with the establishment of Sixty Active S.p.A. Scanty rewards of internal growth, whether regulatory or financial, and operative advantages push the group from the beginning 
towards external growth and a reticular configuration that reproduces the manufacturing structure, made up mostly by a network of independent manufacturing suppliers, co-ordinated by the group head.

The stage of development through vertical integration (Chandler 1962) is instead absent in Sixty's growth. One of the group's secrets of success was actually that of remaining light and flexible, never internalising either the manufacturing base (organised season by season, according to needs and thanks to an international, national and local production fabric, already rich of manufacturing expertise and operative flexibility) or the creative base, also open to welcoming the younger and original talents in the market.

Continuous research of originality, transparency towards the outside, openness towards new ideas and personalities, according to contractual forms that are always flexible even in the more purely organisational and managerial roles, "lightness" are values at the base of Sixty's culture and they are not very compatible with the Chandlerian model of vertical integration and "hierarchization" .

In the fashion sector, market transactions appear to be both more efficient and more effective than hierarchy based transactions and it is this that generates organisational networks rather than big companies integrated in the classical Chandlerian tradition and typical of its industrial sectors (motor, oil, chemical, large scale retail trade). It is not the lack of capital or a managerial culture suitable for the management of big business but the actual essence of transactions in the fashion sector and the continuous pursuit of creativity and flexibility that defines nonhierarchical network structures (see Cerruti and Harrison 2006, for an analysis of Gucci's structure).

Coase's (1937) perception and his conceptual approach grasp the nature of these transactions. These have a low level of "specificity" (the same machinery of the manufacturing supplier can be used for different brands and productions), a controlled and programmable "frequency" (launch of sample collections and new information instruments of production management allow the effective management of large networks of manufacturing suppliers that are external to the company) and low "uncertainty" (many manufacturing suppliers available on the Group's side, many groups needy of manufacturing services on the suppliers' side) and therefore they are more manageable with market transactions. If it is true that the harmonisation of the contractual interfaces that bind the parties, in such a way as to influence adaptability and promote continuity, is a source of real economic value (Williamson 1986), and this occurs mostly within companies, the same result is reached in a large part of the Italian fashion sector from market transactions, thanks to both their repeated and systematic character and to that "trust" (Dei Ottati 1994) of socio-territorial origin capable of reducing many of the typical market transaction problems (limited rationalisation, opportunism, information asymmetry and moral hazard).

The process of the group's restructuring, with the merging of three of the main companies, following their constant and strong growth, and the internal reorganisation described in the preceding paragraphs also eludes analysis using the classical models. In place of the divisional structures provided with autonomy, foreseen by the Chandlerian view facing growing international volumes and diversification, we 
have mergers and rationalisations of company functions. Once again the model of internal growth within a large enterprise does not occur. Scott's (1971) distinction between "divisionalisation", as the choice of an efficient structural typology and "decentralisation", or the different stages of development, tied to production portfolios, foreseen by Channon (1973), do not adapt themselves to analysing forms of businesses that emerge from the market and that continue to use market transactions even when under the management of the same economic entity. One thinks of Sixty's new structure, for example (Fig. 1), where the Brand VPs negotiate on a contractual basis with the Operations $V P$ and where a large part of the manufacturing activity is externalised and regulated contractually.

The most efficient key to reading the Group's development remains that of the industrial network that, according to the nature of the transaction costs involved (frequency, specifics, uncertainty) reorganise and remodel itself, pursuing efficiency and effectiveness, in a structure that is always flexible, never crystallized in the impossible pursuit of "controlling" the creative processes that in the fashion sector tend to be "uncontrollable" on account of their nature and open to external contamination.

Functions such as administration, finance, accounting and purchasing were better managed by individual companies during the launch phase of new brands where the safeguard of initiatives required separating said functions of the main brands' ordinary activity, through assigned partnership structures. Growth in size and internationalisation generate instead, duplications and losses of opportunities in terms of economies of scale and specialisation. Hence the need of merging and reorganising functions to regain efficiency and effectiveness.

Sixty's process of internationalisation confirms our second hypothesis with regard to the interpretative superiority of Uppsala's model (Johanson and Vahlne 1990) in describing the internationalisation of "industrial networks" of Italian companies in the fashion sector.

The modalities of internationalisation were a necessary consequence of the reticular structure described above: these were incremental and on progressive levels of engagement, linked to purchasing times and processing of knowledge and connections on behalf of the network. The stages were those typical of Uppsala's model of internationalisation (Johanson and Vahlne 1977): commercial penetration through indirect channels, direct export with their own agents, marketing branches, production agreements and, finally, their own production establishments.

The choice of countries was tightly linked to reasons of cultural affinity and geographical proximity: firstly the domestic and European markets, then the North American, and lastly the Chinese and Eastern markets with their different approach to "casual wear".

\section{Conclusions}

The present business case makes a contribution to research on the relationship between strategy and structure in the made in Italy fashion sector, referring specifically to the internationalisation process. 
The case proves our first hypothesis: the causal strategy-structure connection remains valid and appropriate for the study of the processes of internationalisation of Italian companies in the fashion sector; the structures adapt themselves to the emerging strategies of internationalisation.

The case proves our second hypothesis: the classical stages of business development do not adapt themselves to the "industrial networks" of Italian companies in the fashion sector; Uppsala's model of incremental internationalisation appears to be the most effective explanatory paradigm (Johanson and Vahlne 1990).

"Literal replies" and "theoretical replies" (Yin 1989; Eisenhardt 1989) of this and other business cases will be necessary before drawing temporary theoretical conclusions on the evolution of the strategy-structure relationship within the processes of internationalisation of businesses in the Italian fashion sector.

The subject is of great relevance for many small and medium size industries that are found in the fashion sector and that have difficulties in finding a strategystructure fit capable of opening them up to new and big opportunities of the emerging markets.

\section{References}

Aldrich H, Whetten DH (1981) Organization-sets, action-sets, and networks: making the most of simplicity. In: Nystrom PC, Starbuck WH (eds) Handbook of organizational design. Oxford University Press, Oxford

Ansoff HI (1965) Corporate strategy: an analytical approach to business policy, growth and expansion. Mc Graw-Hill, New York

Becattini G (2000) Distretti industriali e sviluppo locale, Bollati Boringhieri, Torino

Bellandi M, Caloffi A (2006) Distretti industriali italiani e internazionalizzazione fra gli anni novanta e la prima metà del nuovo decennio, in Rapporto ICE 2005-2006 (2006 L'Italia nell'economia internazionale, Roma, ICE, pp 466-482

Boari C, Grandi A, Lorenzoni G (1989) Le organizzazioni a rete: tre concetti di base. Economia e politica industriale 64:283-310

Cafferata R, Genco P (1997) a cura di Competitività, informazioni e internazionalizzazione delle piccole e medie imprese, Il Mulino, Bologna

Cafferata R, Mensi R (1995) The role of information in the internationalization of SMEs: a typological approach. Int Small Bus J 13(3):35. http://www.proquest.com/ (accessed 19 August, 2009)

Camuffo A, Furlan A, Romano P, Vinelli A (2006) The process of supply network internationalization. J Purch Supply Manage 12(3):135-147 (ebsco)

Cerruti C, Harrison A (2006) Agile supply chain in the fashion business. Supply Chain Pract 8(1):4-21

Chandler AD Jr (1962) Strategy and structure. Chapters in the history of industrial enterprise, MIT Press (versione italiana a cura di Franco Angeli, IV edizione, 1993)

Channon DF (1973) The strategy and structure of British enterprise. McMillan, London

Coase R (1937) The nature of the firm. Economica 4(16):368-405

Dei Ottati G (1994) Trust interlinking transactions and credit in the industrial district. Cambridge J Econ 18(6):529-546

Dei Ottati G (2003) Exit, voice and the evolution of industrial districts: the case of the post-World War II economic development of Prato. Cambridge J Econ 27(4):501-522

Egelhoff W (1988) Organizing the multinational enterprise: an information process-perspective, Ballington, Cambridge

Eisenhardt KM (1989) Building theories from case study research. Acad Manage Rev 14(4):532-550 
Franko LG (1976) The European Multinationals, a renewed challenge to American and British big business. Greylock Press, Greenwich

Golinelli G (1992) I problemi strategici dell'impresa minore. Sinergie (27):25-31

Hall DJ, Saias MA (1980) Strategy follows structure. Strateg Manag J 1(2):149-163

Johanson J, Vahlne JE (1977) The internationalization process of the firm-a model of knowledge development and increasing foreign market commitments. J Int Bus Stud 8(1):23-32

Johanson J, Vahlne JE (1990) The mechanism of internationalisation. Int Mark Rev 7(4):11-24

Lorenzoni G (1990) L'architettura di sviluppo delle imprese minori. Costellazioni e piccoli gruppi, Il Mulino, Bologna, 1990

Mintzberg H, Waters JA (1985) Of strategies, deliberate and emergent. Strateg Manag J 6(3):257-272

Pavan RJ (1976) Strategy and structure: the Italian experience. J Econ Bus 28(3):254-261

Pepe C (1984) Lo sviluppo internazionale della piccola e media impresa, Franco Angeli, Milano

Rullani E (1997) L'evoluzione dei distretti industriali un percorso tra decostruzione e internazionalizzazione. In: Varaldo R, Ferrucci L a cura di Il distretto industriale tra logiche d'impresa e logiche di sistema, Franco Angeli, Milano

Scott BR (1971) Stages of corporate development, Part I \& Part II. Harvard Business School, Cambridge

Smith GA, Christensen CR (1962) Policy formulation and administration. R.D Irwin, Homewood

Snow CC, Miles RE, Coleman J Jr (1992) Managing 21st Century Network Organizations. Organ Dyn 20(3):5-19

Stopford JM, Wells LT (1972) Managing the multinational enterprise. Basic Books, New York

Suzuki Y (1985) The formation of management structure in Japanese industrials 1920-40. Bus Hist 27(3):259-283

Thorelli HB (1986) Networks: between markets and hierarchies. Strateg Manag J 7(1):37-51

Tichy N, Thusman M, Fombrun C (1979) Social Network Analysis for Organization. Acad Manage Rev 4(4):507-519

Williamson OE (1986) Economic organization: firms, markets and policy control. Harvester Wheatsheaf, New York

Yin R (1989) Case study research, design and methods. Sage, London

Zucchella A (2006) Local cluster dynamics. Trajectories of mature industrial districts between decline and multiple embeddedness. J Inst Econ 2(1):47-62 